\title{
La plaza Vázquez de Molina de Úbeda: nuevos datos para el análisis de su configuración urbanística
}

\author{
ARSENIO MORENO
}

\section{RESUMEN}

La plaza Vázquez de Molina constituye, posiblemente, el más espléndido ejemplo de renovación urbana desarrollado en la España del

Renacimiento

Levantada sobre los terrenos yermos de una :ieja vaguada, los edificios que la

conforman van a ser erigidos en un plazo temporal no superior a los sesenta años. Una copiosa documentación de archivo, junto a recientes exploraciones arqueológicas, nos ha permitido definir una sólida hipótesis sobre su desarrollo arquitectónico, reciamente impregnado de valoraciones simbólicas y un fuerte contenido aulico.

\begin{abstract}
Plaza Vázquez de Molina is probably the finest example of urban renovation in the Spanish Renaissance.

The Plaza, which was built on a barren river bed, comprises a number of buildings which were erected in less than sixty years. The information collected from archives, together with recent archaelogical excavations, has allowed us to state a solid hypothesis on its architectonic development, which is highly symbolic and possesses a strong court content.
\end{abstract}

La plaza Vázquez de Molina había sido hasta el siglo xv una vaguada por donde discurria e! arroyo de la Azacaya.

En las primeras décadas del xvı el terreno era explanado, empleándose -en alguna medida - escombros del viejo alcázar cuya demolición se había completado en 1507 . El nuevo y ámplio espacio surgido era, a todas luces, el menos colmatado y comprometido por asentamientos constructivos de toda la ciudad. 


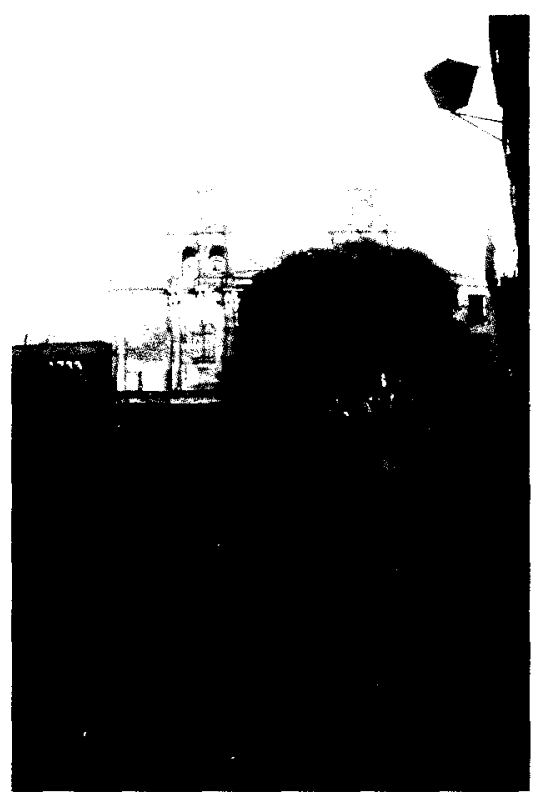

Antes de coronar la primera mitad del siglo, cuando son concluidos en buena medida las operaciones edilicias que hoy configuran su actual imagen, esta plaza constituye el recinto más despejado y extenso de toda la retícula urbana.

Es precisamente en estos años, concretamente en 1558, cuando Bartolomé Ruiz, personero ${ }^{1}$ de la ciudad, emprende un ruidoso pleito contra el mismo Concejo. El motivo, la venta y edificación de ciertos solares, así como el emplazamiento y construcción de un nuevo pósito en este lugar ${ }^{2}$.

El caso, que como tantos otros quedaria archivado en la Real Chancillería de Granada, es de un extraordinario interés tanto por el valor descriptivo y analítico que de este espacio urbano se efectua, como por la innegable preocupación simbólica y urbanistica que de él se desprende.

El Personero, o procurador, era un cargo municipal cuyas referencias más antiguas datan en la ciudad de finales del siglo xıII. Elegido entre los hombres buenos pecheros por sufragio indirecto, entre representantes de las diversas collaciones, sus competencias eran velar por los derechos ciudadanos en el Concejo. Miembro con voz, pero sin voto, en un cabildo plenamente aris tocrático, su presencia en el siglo xvı en Úbeda aún debia de gozar de cierta autoridad moral, aunque ésta resultase ser, en tantos casos, meramente testimonial.

Archivo de la Real Chancillería de Granada. Documento 508/1501/9 
En estos momentos ya ha sido levantada la fábrica de la Sacra Capilla de El Salvador, erigida por iniciativa de don Francisco de los Cobos y el palacio de su capellán mayor, don Fernando Ortega Salido; también está siendo construida de cimientos las capillas de Santiago o del Sagrario, en Santa María de los Reales Alcázares, por iniciatica la primera del obispo don Diego de los Cobos.

La plaza es definida en el documento como lugar público, escenario de ferias de ganado y ventas de toda granjería; pero también como nuevo espacio emblemático de la urbe ${ }^{3}$.

En el citado año de 1557 el Concejo ha comenzado a poner en venta una serie de solares en la acera del alcázar, frente a las "casas» del deán Ortega. A esto el personero se opone esgrimiendo de un modo contundente los siguientes argumentos: «...que estando proybido por derecho antiguo y leyes que las plaças públicas y calles y otros lugares publicos no se ocupen ni hedifiquen sino que se conserven para el uso publico de los vezinos y moradores del tal lugar es ansi que en la plaça publica y rrua de la dha. çibdad de uveda en çierta parte della hasta llegar al rrastro y a la puerta behuz las partes contrarias de pocos dias a esta parte an dado e rrepartido muchos solares a vezinos de la dicha çibdad con cierto cargo e tributo sin tener para ello licencia ni facultad... con los cuales ocupan mucha parte de la dicha plaça e rrua e ynpiden el trato y comercio de los vezinos e forasteros que vienen a vender sus mercadurias en ella porque no queda sitio... y demas desto junto a la puerta del alcazar viejo que fue mandado derrocar y se derroco por mandado de los rreyes catolicos por rrazon de los vandos y parcialidades que en la dha. çibdad avia agora nuevamente la dha. cibdad a empeçado a hazer e hedificar una casa de posito para el pan... y dado y rrepartido ciertos solares alrrededor de lo que se derroco del dho. alcazar que en efecto es bolvello a cercar... ${ }^{4}$.

En efecto, cuando fué demolido el alcázar, concediendose a la ciudad la piedra, madera y ladrillo, del mismo por doña Juana, las actuaciones se priorizaron entre la Torre de lbiut y el postigo del Alcázar, que era la muralla que separaba la fortaleza de la ciudad; es decir, entre la calle Baja del Salvador y el actual palacio del Marqués de Mancera. El levantamiento. por tanto, de nuevas casas significaba un nuevo cerramiento del viejo recinto defensivo, asi como la ocupación de unos solares cedidos - por lo

Moreno Mendoza, A.: Ubeda renacentista, págs. 88-96. Electa, Madrid, 1991

lbidem. 
demás- por la Corona, para su venta en almoneda y posterior inversión en una renta para los propios de la ciudad ${ }^{5}$.

Ante este estado de cosas Bartolomé Gil suplica que todas estas nuevas edificaciones sean demolidads, incluyendo naturalmente el nuevo pósito del grano, pues como asegura el personero en una nueva instancia trasladada a la sesión del mes de marzo de 1558 «...en el lugar donde se haze la dha. casa no se puede conservar el pan porques muy umido y ( $\sin$ ) arte que mucha parte del pan que en ella se pusiese se a de perder por rrazon que el lugar donde se haze esta ocupado por tres partes para que no le pueda vonar los aires que son a la parte del alcazar en la capilla del comendador covos y de la casa del dean y solamente queda libre la parte de hazia el abrego y fecha la capilla de di de los covos queda la dha. casa por todas partes embaraçada de forma que el ayre no la pueda vonar y es causa de muy grande perdida para el pan... ${ }^{6}$.

Antes de proseguir, creo conveniente aclarar que la capilla a la que se nos está haciendo referencia en el documento como propiedad de Diego de los Cobos, que naturalmente aún está por ejecutar, es el proyecto emanado del que pasados unos años sería obispo de Jaén, el cual había obtenido en Santa María de los Reales Alcázares la cesión de una vieja capilla -apenas un simple altar junto al testero del evangelio - por extinción de su patronato en 1548. Conseguido este derecho, en Concejo a través de una donación a su hermano Juan Vázquez de Molina, en sesión de 1 de septiembre de 1546 le otorga "una Calleja, suelo y sitio publico", junto a la barbacana, tal como se desprende de una provisión del Emperador en la que se confirma dicha concesión?

Todavía se haría precisa una segunda cesión municipal, habida cuenta que, hechas las trazas y abiertas las zanjas, se comprobó que la capilla ocupaba más terreno que el solicitado antes por Juan Vázquez.

En cualquier caso los trabajos son paralizados una vez acometido el portentoso proyecto del Hospital de Santiago por el ya entonces prelado, quien dejaria por testamento a la Colegial el solar «en linde de la iglesia mayor della y de las beatas de Sancho Iñiguez». El abandonado proyecto sería asumido por el comendador don Rodrigo de Orozco, una vez conseguidos los derechos por parte del cabildo colegial para la fundación de su capilla familiar ${ }^{8}$,

Ruiz Prieto, M.: Historia de Úbeda. Úbeda, 1906. Ed. Pablo de Olavide, 1982, pág. 180

Idem. Copia de la sesión de cabildo celebrada el 28 de enero de 1558.

Ruz Prieto. lbidem, pág. 288.

8 Archivo Municipal de Úbeda. Documento sin numerar. Estatutos del Hospital de Santiago (Copia autentificada de 1844). Memorial de los bienes raices, juros y censos que nos D. Diego de 
quién -no sin dificultades económicas- conseguiria concluir la actual edificaciòn pasados varios años.

Pero volviendo a los argumentos del personero sobre la ubicación del nuevo pósito tendríamos que indicar que el edificio, y ese era el principal problema, más que lindar con otras construcciones, se había erigido de forma absolutamente exenta sobre terreno público, provocando un claro estrechamiento de la gran plaza y una neta separación en el mismo vértice de lo que se llegaría a conocer como "claro del Salvador" y "claro de Santa María»; es decir, una compartimentación en dos espacios diferenciados.

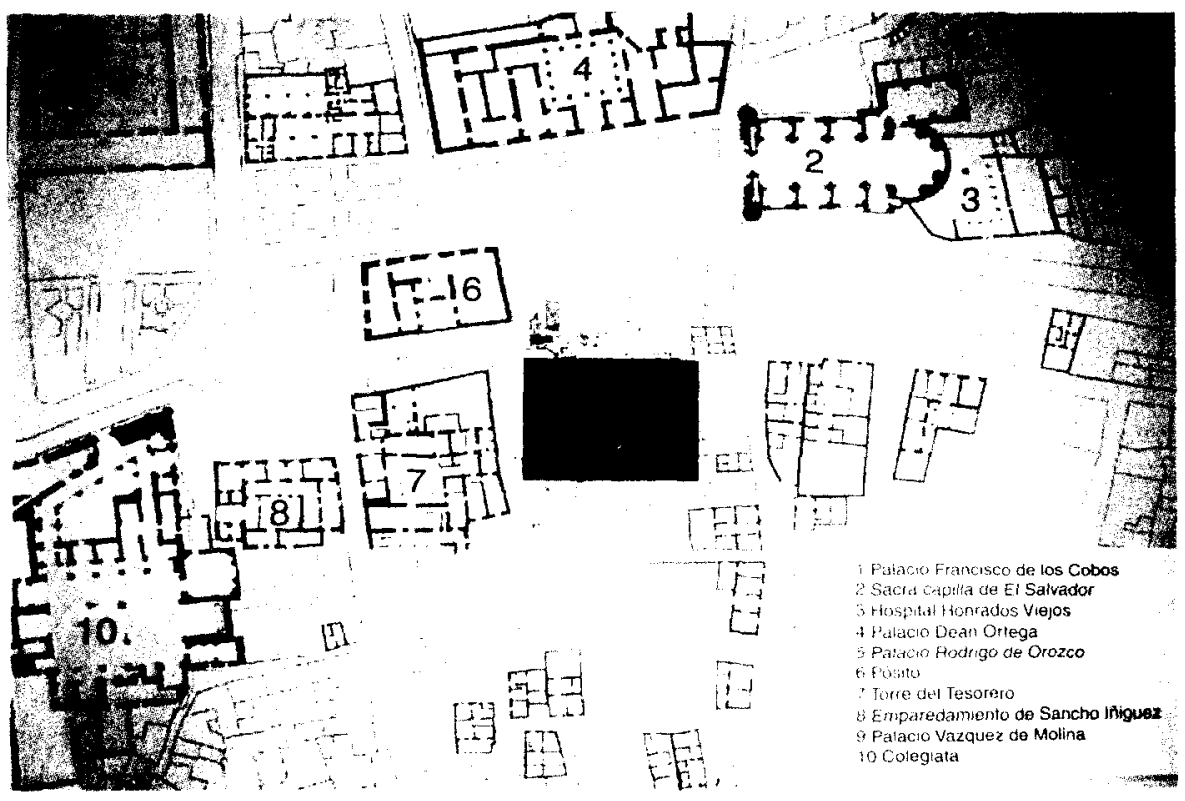

Por lo demás, la edificación de la Alhondiga habría de ser, si atendemos otros modelos de la época como el de la Iruela -obra del mismo Vandelvira- o Baeza, construcciones muy simples, funcionales y de aspecto fabril, carentes de toda retórica monumental.

En otro orden de cosas, nos dice el personero, las casas que se entán construyendo son "como en arrabal y aldea y encubren las principales casas 
questaban fechas donde el ornato del pueblo se menoscaba». Son casas, pues, de infima calidad, construcciones débiles, como había llegado a declarar pericialmente el propio Andrés de Vandelvira.

Estudiado el caso es resuelto por los regidores Gil de Valencia, Diego López de Sanmartín y Francisco Vela de los Cobos, la demolición de todas estas edificaciones. La ciudad habría de recuperar los solares vendidos en almoneda e indemnizar a sus propietarios devolviendoles el precio pagado por los mismos, así como los gastos ocasionados por las obras.

Sólo dos edificios van a ser excluidos de este dictamen: El primero es el Pósito, toda vez que ya estaba levantado y, salvo fallos de cimentación detectados por Vandelvira y Pedro de Mazuecos, que habrían de ser subsanados a costa de los maestros en que se remató la obra, el dasaguisado constituia por si un hecho consumado y de dificil reparación y, allanado el terreno -dicen los regidores-, se solventarian las dificultades ${ }^{9}$. El segundo, al que se hace referencia de soslayo, son unas "casas principales", con toda certeza la mansión de don Rodrigo de Orozco, a las que dedicaremos un comentario más extenso ${ }^{10}$.

La victoria del personero, aunque incompleta, había sido significativa en pos de la defensa de! principio de decoro urbano y, con ella, de los intereses ciudadanos.

Pero analicemos de un modo más detenido la gestación morfológica de esta plaza, su proceso edilicio de un modo cronológico.

\section{EL LLANO DE EL SALVADOR}

\section{El complejo edilicio de la Sacra Capilla de El Salvador}

En su lado este, presidiendo el eje de axialidad longitudinal del lugar, se había levantado la Sacra Capilla de El Salvador.

Este panteón funerario, fundado por el comendador don Francisco de los Cobos, omnipotente secretario del emperador Carlos $V$, había constituido una extraordinaria y compleja operación urbanistica, toda vez que incluia en su proyecto la realización de un nuevo palacio, la remodelación de un viejo hospital, y la creación de un Estudio General. Y todo ello dentro del tejido de

Parejo Delgado. María Josefa: Baeza y Ubeda en la Baja Edad Media. Editorial Don Quijote. Granada, 1988. pág. 49.

Idem. Traslado de la sesión de cabildo del dia 17 de marzo de 1558 


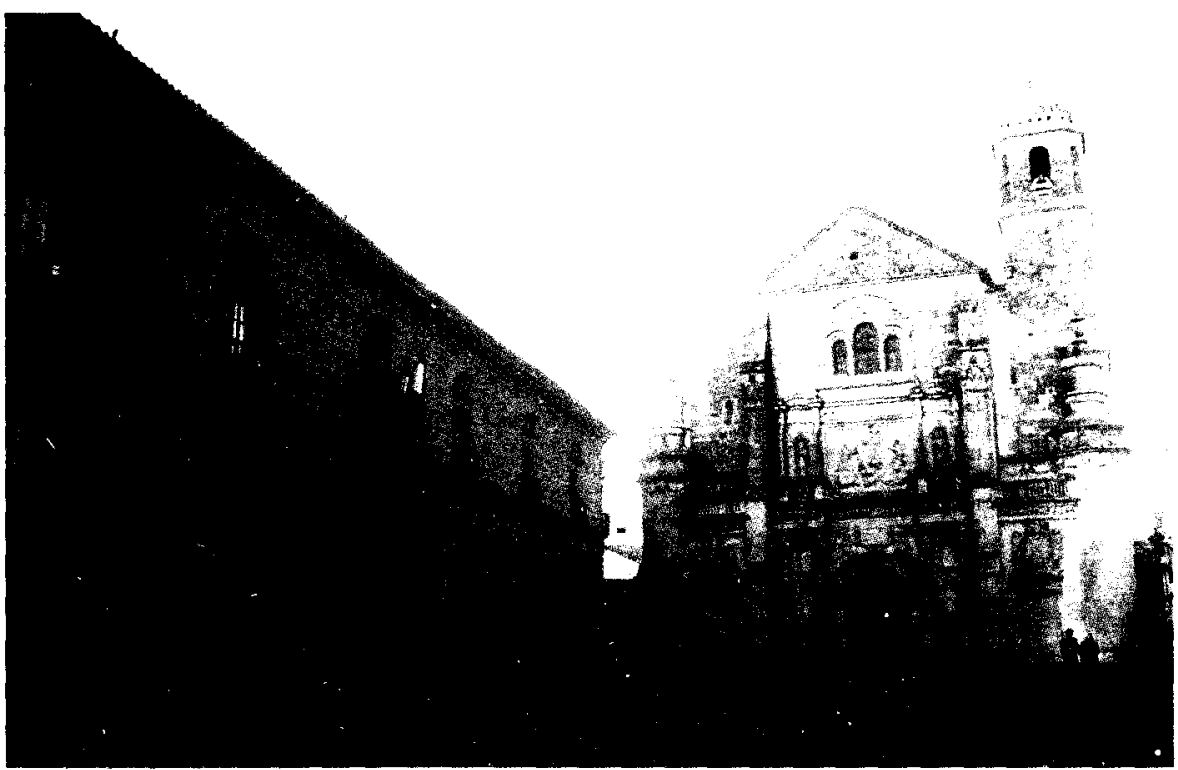

un viejo barrio, el "barrio de los Cobos», de la coliación de Santo Tomás, una manzana de la antigua reticula urbana tan colmatada como irregular.

Cobos inicialmente poseia una vieja casona, solar de sus antepasados. Sus pretensiones en 1525, cuando su propietario, secretario y miembro del Consejo de su Magestad. ya ha contraido matrimonio con doña María de Mendoza y Pimentel, tan sólo se limitaban a obtener una pequeña parcela aneja a la parroquia de Santo Tomás, donde poder levantar y dotar una capilla funeraria familiar ${ }^{11}$. Diez años más tarde, una vez caido en desgracia el canciller Gattinara, para Cobos, convertido --junto a Granvella- en el más prominente y todopoderoso consejero imperial, acaudalado propietario. señor de varias villas, Comendador mayor de León, Adelantado de Cazorla. y un largo etc., estos planes primordiales ya habian cambiado de dirección. tornandose mucho más ambiciosos al conseguir la bula de Paulo III para erigir no ya un modesto enterramiento, sino todo un panteón, a imagen y semejanza del que era levantado por su señor en la catedral de Granada.

La nueva iglesia, junto a la ampliación de la antigua casa paterna, requería una superficie de suelo urbano inusualmente amplia en la colmatada estructura urbana. $Y$ para ello, desde 1518, el Comendador emprende un 
proceso de adquisición de fincas que habría de concluir en 1535. Un total de 11 casas han de ser compradas durante estos años, casas de diversa magnitud y extensión, cuyos precios oscilarían entre los 5.000 maravedies de la más modesta y 204.000 de la más costosa ${ }^{12}$. El importe desenvolsado en su totalidad rondaría la cifra, nada desdeñable, de 1.500 ducados.

En un primer momento, hasta 1526, las primeras fincas conseguidas no sin dificultad están destinadas a dotar de suelo al proyecto residencial o palaciego; más adelante, las restantes, junto a los terrenos cedidos por los cofrades del Hospital de los Horados Viejos - a cambio de importantes contrapartidas-, serán puestas a disposición del nuevo templo.

En un principio, allá por el año 1531, el arquitecto real Luis de Vega era enviado a la ciudad para elaborar trazas para la ampliación de la antigua mansión paterna, remitiendo en agosto de 1532 al Comendador el deán Ortega un pequeño plano donde es contemplado un "rasguño" de nuevo cuerpo posterior a añadir ${ }^{13}$. Acompaña a este documeto una extensa carta de don Fernando donde expone una serie de prolijos detalles sobre la nueva obra. "El cuarto es començado a labrar como lo traço Luis de Vega" - le dice-; y, tras apuntar algunos pequeños problemas como la compra de un trozo de corral a un tal Martín Ortega, añade: "No tome cuidado que acá lo haremos como convenga ni es razon que por lo menos se dexe de poner esta casa en perfecion" '4. Antes, en 1531, tras conseguir las dos últimas parcela vecinas ${ }^{15}$, el Concejo, Justicia y Regimiento de la ciudad, hace gracia a don Francisco de los Cobos de una porción de agua de la fuente de la Plaza de Toledo para la conducción a sus casas ${ }^{16}$. Este caudal sería aumentado en 1540 con una nueva merced, esta vez a doña Leonor de los Cobos, de las derramas de la Fuente Nueva ${ }^{17}$.

Vega va a plantear la reordenación y ampliación de la nueva casa concibiendola en un doble cuerpo: en el primero es respetada la existencia de la vieja residencia familiar. El segundo, en cambio, levantado de cimientos, presenta un patio con doble arquería (arcos de medio punto en su planta baja, de carpanel en la superior), muy en consonancia con el palacio trazado por el mismo maestro para Cobos en Valladolid años antes.

Archivo Ducal de Medinaceli. Sección Sabiote. Leg. 16.

Archivo General de Simancas. Mapas, Planos y Dibujos. XVIII-83. Úbeda, 1 de agosto de 1532. Según diseño de Martin Ortega y Luis de Vega.

Archivo General de Simancas. Sección Estado. Leg. 25, fols. 234-237.

Archivo Ducal de Medinaceli. Sección Sabiote. 3-8-55 y 56.

Archivo Ducal de Medinaceli. Sección Sabiote. 3-8-76.

Idem. $3 / 8 / 77$. 
Del palacio ubetense, calificado ya en 1845 por Richard Ford como una mansión "cruelmente degradada" ${ }^{18}$, conservamos una puntual descripción en uno de los inventarios de las propiedades de Camarasa fechado en $1752^{19}$. Y de él, Francisco de los Cobos y Luna, en 1601, nos dice que es tan excelente como el levantado por su abuelo en Valladolid "y aún mejor que él»" ${ }^{20}$. Ambos cuerpos serán literalmente ocultados por una extensa y opaca fachada de oscura sillería, cual si de una auténtica mampara se tratara.

La Sacra Capilla del El Salvador, trazada por Diego de Siloé, es construida entre 1536 y 1559, año de su consagración, por los maestrso Alonso Ruiz y Andrés de Vandelvira; aunque sus obras se prolongaría todavía durante la siguiente década.

Para poder levantar tan imponente fábrica Cobos - ya lo hemos apuntado- ordenaba en 1534 a su apoderado y capellán Fernando Ortega que entrara en negociación con la Hermandad de los Venerable Viejos del Divino Salvador de la ciudad, cuyos terrenos eran colindantes con las propiedades del Comendador.

El deán, tras diversas tentativas, obtiene el éxito deseado. En agosto de este mismo año los responsables de la hermandad se dirigen por carta a Cobos comunicandole su voluntad de cederle el suelo necesario ${ }^{21}$.

La aceptación solemne, junto a las condiciones impuestas, es remitida al Comendador. Cobos debía labrar una iglesia de la misma extensión que la parroquia de San Pablo y hacer entrega de una donación anual de 100 ducados a la hermandad, asi como diversas dotes para doncellas pobres.

En 1548 Vandelvira redactaba las condiciones para erigir «el quarto de la iglesia del ospital de san salvador que mandan hazer los señores cofrades». Con el levantamiento de esta pequeña capilla, materializada por los canteros Francisco Zambrano y Miguel Ruiza, da comienzo un importante programa de ampliación y mejora de esta venerable institución medieval, puesta ahora bajo la tutela y patrocinio - tal como se refleja en los estatutos fundacionales de la Sacra Capilla- del todopoderoso Secretario de Estado del Emperador.

\footnotetext{
18 Ford, R.: Manual para viajeros por Andalucia y lectores en casa. Reino de Granada. Ed. Turner, Madrid, 1980, pág. 180.

19 idem. 3/8/2A.

20 KENISTON: Op. cit., pág. 146

21 Keniston: Op. cit., págs. 158-159.
} 
Finalizada la iglesia le toca el turno al patio. Y es en 1552 cuando Diego de Escalona, un cantero local, se compromete a edificar la galería este del mismo. Esta debe ser concluida en su planta baja en 1561, completandose las restantes -de concepción claramente serliana- 20 años más tarde ${ }^{22}$.

Pero el proyecto global de Cobos era aún mucho más ambicioso y polivalente.

El Comendador, en los Estatutos Fundacionales otorgados en Valladolid en 1544, había dispuesto edificar y dotar un monasterio "de barones - Mujeres, según que ante mi paresciere». De este nunca más se tuvo noticia.

Tambien el fundador se había dirigido a Paulo III solicitando licencia para establecer junto a su capilia, "una cátedra o estudio general en donde se leyesen lecciones y se diese cualquier grado de enseñanza así como en Bolonia, París, Salamanca o Alcalá", obteniendo respuesta satisfactoria del pontífice en 1541.

Fallecido el mecenas, cuando su viuda doña María de Molina visita Úbeda en 1570, deja ordenado "que de aqui adelante se lean las lecciones de gramática, latinidad y retórica que su señoría y el comendador mayor que sea en gloria, instituyeron y mandaron por sus estatutos que se leyesen en esta ciudad acerca de las quales se guardará todo lo contenido en el estatuto que habla de las dichas lecciones y cathedras» 23.

Pero el proyecto era excesivamente grandioso y los recursos, a la postre, limitados.

Este mismo año de 1570, doña María de Mendoza, en carta remitida al capellán mayor Domingo de Ocón, insiste en edificar el mencionado Estudio, o al menos «la casa o escuelas» donde se impartan las clases. Estas, "en forma que mejor le parezca con parecer de oficiales", irían "en las casas que llaman de los Serreras que son entre la dha. Yglesia y mis casas principales", debiendose construir "un aposento comodo en que puedan vivir ei chatedratico que fuere de aqui adelante en los estudios generales, en que El y su repetidor lean y los demas conforme a la disposicion del sitio que fuere necesario para provecho de la chatedra y bien de los estudiantes..." ${ }^{24}$. 


\section{Palacio del Deán Ortega}

Vinculado a la Sacra Capilla, en su ángulo norte, el primer capellán mayor de la iglesia, don Fernando Ortega Salido, deán de la catedral de Málaga, capellán del emperador, y hombre de confianza de Cobos en la ciudad, levantará su nuevo y suntuoso palacio.

Este bello ejemplar de nuestro Renacimiento, con su disposición horizontal abierta a dos fachadas, ya debia estar sustancialmente acabado en 1550, pues en este año el cantero Martín de Mendiola se compromete a enlosar el patio "con la bajada de la escalera del patio al zaguan e con la otra bajada del transito de entre los dos patios e dasaguadero del dicho patio a la calle» ${ }^{25}$. Las obras, por tanto, han de desarrollarse en la década de los cuarenta. No obstante, aún en 1553, es proyectada la ampliación o reforma de la fachada oeste, donde el deán labra otras «dos casas tiendas que limitan con ella - la principal- en boca de la rrua donde era pescaderia" ${ }^{26}$, encargandose al cantero Pero Jorge su ejecución y siguiendo en todo punto el modelo establecido en la fachada principal ${ }^{27}$.

Para poder llevar a cabo estas empresas edilicias, un año antes había sido adquirido el local ocupado de antaño por las pescaderías de la ciudad, que han sido permutadas al deán por el cabildo a cambio de un haza con fuente en el Despeñadero ${ }^{28}$.

Desconocemos su tracista. Sin embargo, en 1555, cuando son dadas las condiciones para la ejecución de puertas y ventanas, se ordena que éstas han de ser "como Luis de Vega lo dejó ordenado" ${ }^{29}$.

Es dificil creer que el arquitecto regio fuera el verdadero tracista de estas obras, toda vez que Andrés de Vandelvira está dirigiendo por estos años la construcción de la Sacra Capilla, bajo la atenta mirada del deán, y otras empresas familiares como el palacio Vázquez de Molina. Sin embargo es más que aceptable pensar en una estrecha supervisión por parte de Luis de Vega de estos trabajos, ya que - no en vano-Cobos lo había

Archivo Municipal de Ubeda. Sec. Protocolos, leg. 266. ante Juan de Ortiz

Archivo Municipal de Ubeda. Sec. Protocolos, leg. 995, fol. 32. Aumento de bienes del patronazgo. 1568.

AA.VV. Guía Historico-Artistica de Ubeda. Asociación Cultural Alfredo Cazabán, Úbeda, 1993. pág. 27.

Archivo Municipal de Úbeda. Carpeta 6-23. 25-X1-1552.

Archivo Municipal de Ubeda. Sec. Protocolos. Leg. 266. Sif. Ante Juan Ortiz. Carpintero. Juan Bautista de Ocon. 
enviado a Úbeda para el examen de las trazas y modelos de su capilla "Como persona expedida en el arte de la cantería" ${ }^{30}$.

\section{El palacio de don Rodrigo de Orozco}

Situado frente a este palacio otro comendador santiaguista, Rodrigo de Orozco, labra sus «casas principales» sobre «un solar de los que rrepartio en la hazera del alcaçar en la calle que va desde la rrua a la yglesia del Salvador el qual alinda con la obra de las casas del posito que la dicha ciudad labra por la una parte y por la otra con otros solares que yo el dicho don rrodrigo tengo" ${ }^{31}$.

Don Rodrigo de Orozco Mexía de Molina era hijo del licenciado Pedro de Orozco, primer caballero de este linaje avecinado en Úbeda, quien había establecido mayorazgo en 1503. Don Rodrigo, que era caballero venticuatro de la ciudad y Comendador de Santiago en Villahermosa, se había comprometido con el Concejo a abonar a la ciudad el importe de una censo perpetuo por esta parcela, razón por la cual no es requerida nuevamente la misma.

Efectivamente, según se ha podido comprobar feacientemente gracias a una excavacion de emergencia realizada en el 2001 , se han hallado los restos de esta construcción, cuya ubicación real resulta ser extraordinariamente esclarecedora para analizar la génesis de este espacio urbano.

Primeramente hay que indicar que el recinto fortificado del alcazar se encontraba a una cota de altura superior al de la plaza, incluso despues de su allanamiento. Este recinto quedaba bordeado por una estrecha calle, "que va de la rrua a la yglesia del Salvador». Frontero a ésta debió de existir un terraplen sobre el cual han aparecido importantes restos del muro de la fortaleza desmochada.

Ni qué decir tiene que el alineamiento actual de casas en la acera contraria al palacio del deán Ortega no existía en aquellos años. Muy por el contrario, los restos del palacio de Orozco quedaban alineados con la Torre del Tesorero - hoy Palacio de Mancera-, constituyendo un espacio casi rectangular mucho más amplio.

30 Keniston: Op. cit, pág. 269.

31 Archivo Municipal de Úbeda. Venta de solares a censo, fols. $151 \mathrm{v}$ y s.s. 

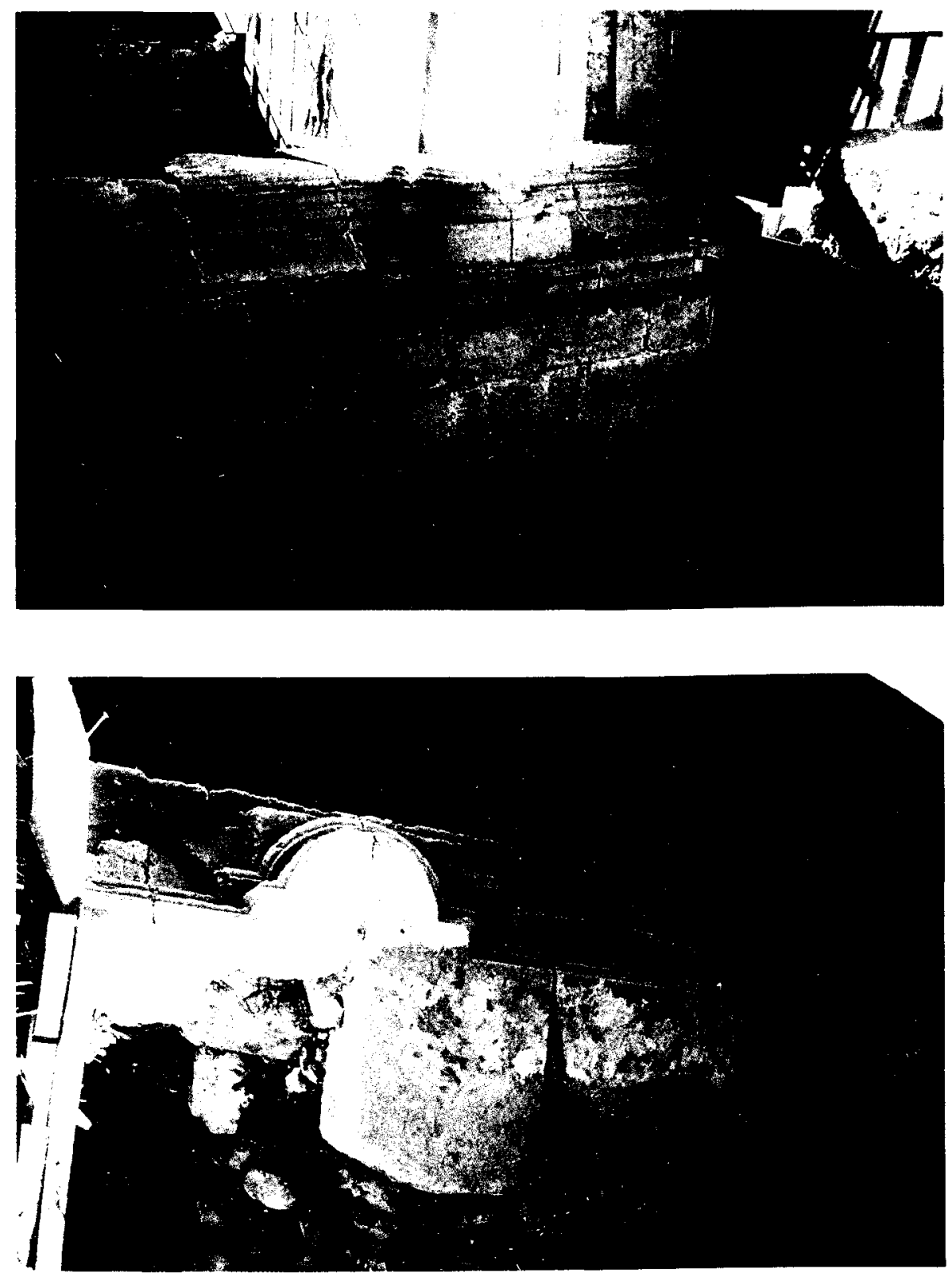

Es ahora cuando comprendemos de un modo claro las quejas del personero ante la ubicación del nuevo pósito, pues su fábrica - de un modo 


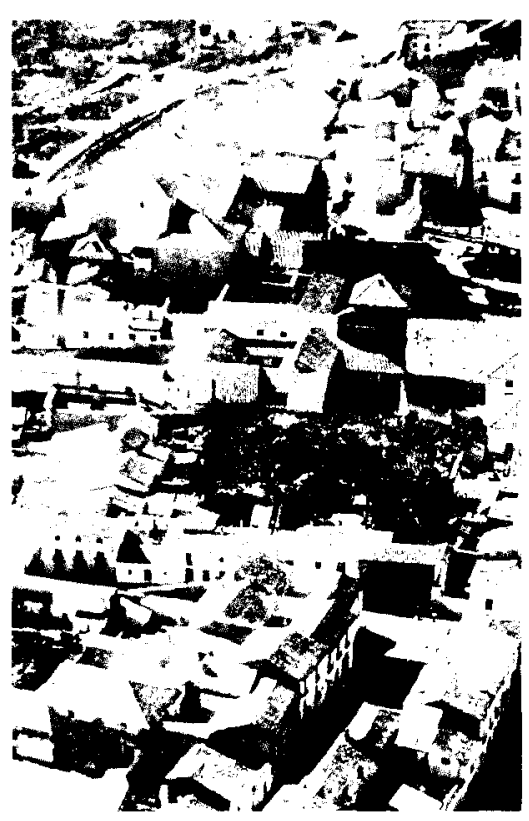

practicamente exento- quedaba erigida en el mismo centro de la plaza, embarazando lo que antes era un espacio abierto y despejado.

El edificio proyectado debió construirse en la década de los cincuenta. En 1555 el cantero Martín de Zalbide se comprometía a entregar cinco columnas de piedra franca de una sóla pieza para este edificio ${ }^{32}$. Otros datos sobre la construcción de este palacio, generosamente facilitados por Vicente M. Ruiz Fuentes, surgirían dos años más tarde cuando el cantero de Jódar Juannes de Aya apoderaba a un colega de la ciudad para cobrar del tambien cantero ubetense parte de la deuda por la labra de una cornisa del palacio ${ }^{33}$.

Las obras continuaba en 1560 al parecer en manos del prestigioso cantero Pedro de Mazuecos, quien subcontrataría a otros maestros como Pedro Hernandez de Cantabrana, o Juan de Alarcos, para la realización, el primero, de medias columnas y traspilares para las esquinas del edificio ${ }^{34}$, o la labra de diversas ventanas, altas y bajas, el segundo ${ }^{35}$.

Archivo Municipal de Ubeda. Sec. Protocclos. Leg. 265. f. DCCLXXXV-V.

Archivo Municipal de Úbeda. Sec. Protocolos, Leg. 242, s/t.

Archivo Municipal de Úbeda. Sec. Protucolos, leg. 309, fol. UXIV

Archivo Municipal de Úbeda. Sec. Protocolos. leg. 309. tol. DXIX. 
La última referencia notarial se produciria un año más tarde, cuando el cantero Juan Polo otorga carta de pago por lo que se le adeudaba en razón de la labra del hastial y otros materiales ${ }^{36}$.

El palacio, en mi opinión, nunca fué concluido. Sus obras debieron ser detenidas quién sabe si por problemas económicos y, tal vez, parte de sus materiales reutilizados. Lo cierto es que, tras la elemental cata arqueológica efectuada, sólo podemos comprobar la existencia del zócalo y el arranque de pilastras del primer cuerpo de su fachada. Es absolútamente probable que una intervención arqueológica de mayor alcance y amplitud nos podría devolver nuevos datos sobre la configuración de esta construcción.

A la postre, el espacio urbanistico resultante en este "llano del Salvador", una vez levantados sus más representativos edificios, distaba mucho del que hoy podemos contemplar. $Y$ ello porque, aún conservando las alineaciones

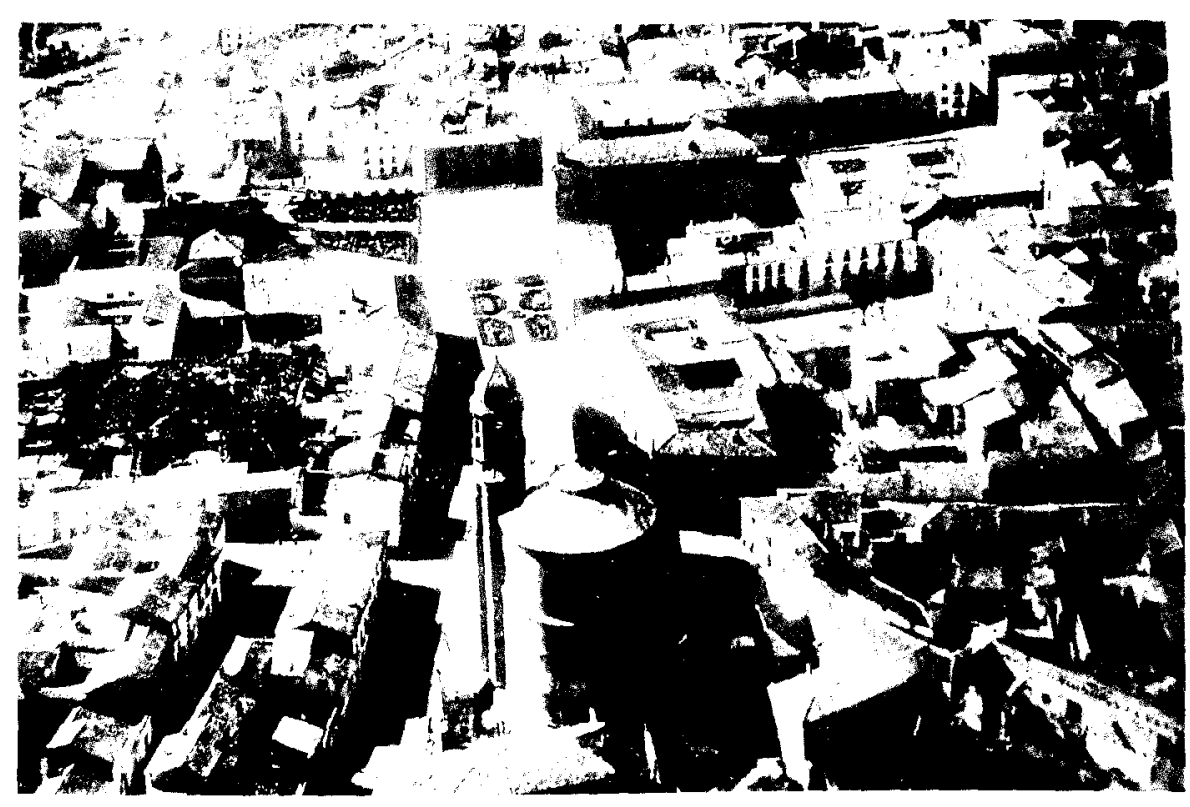

de los dos palacios con respecto a la Sacra Capilla una cierta impontra trapezoidal, la anchura de la plaza era muy superior, acentuando más - si cabe- el dialogo y la proximidad de la iglesia y el palacio de su capellán 
mayor, asi como el desplazamiento del templo, desplazamiento muy similar al que mantiene el Duomo en la Piazza Sodello de Mantua, un ejemplo éste que ofrece numerosas concomitancias con el modelo ubetense.

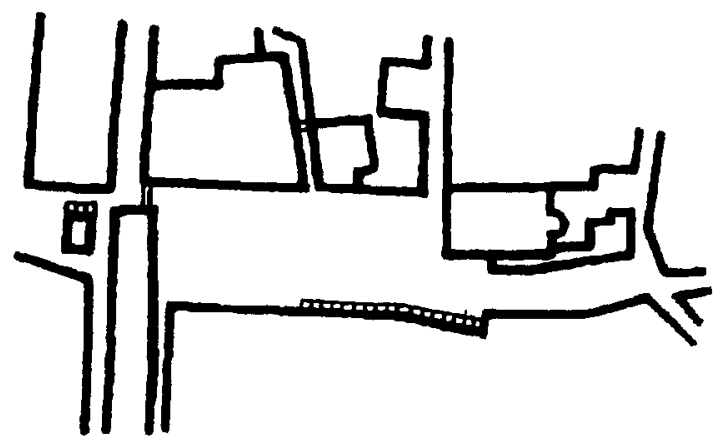

Mantova. Piazza Sordello.

Sin embargo la implantación de estas nuevas edificaciones en la trama medieval parece convivir en singular equilibrio, sin duda alguna fruto de una calculada (o no) proporción volumétrica. Su configuración trapezoidal, que inevitáblemente nos trae a la memoria la Pienza de Rossellino, marca

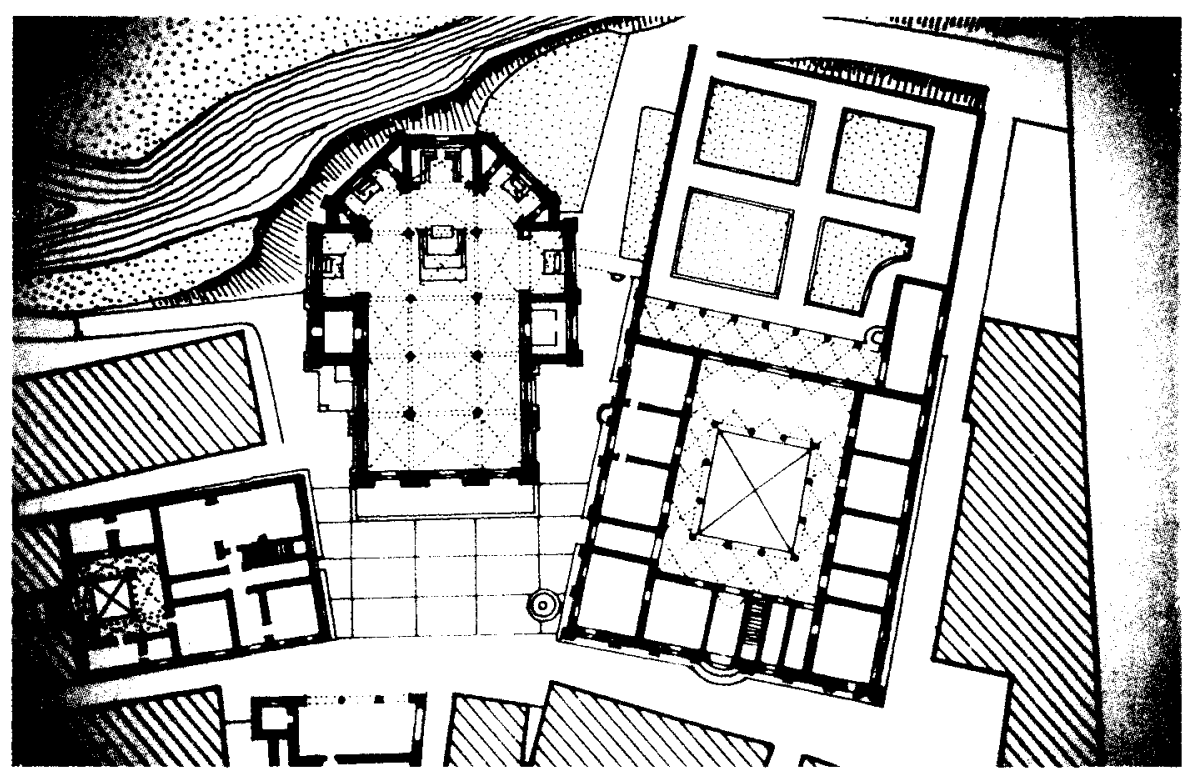


una organización perpectiva que prima, obviamente, la presencia de la gran fábrica de El Salvador.

Esta configuración ligeramente trapezoidal, sin ser frecuente en el urbanismo renacentista, encontraría un precedente extraordinariamente claro en modelos italianos como el ya mencionado de Pienza u otros, más modestos y precisos, como la piazza Matteotti de la pequeña localidad de Sarzana.

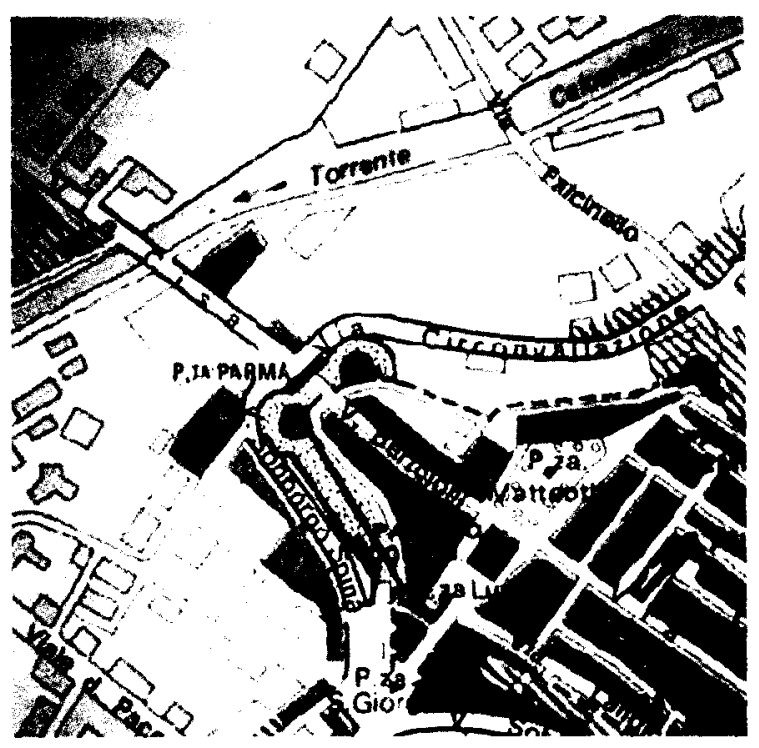

\section{EL LLANO DE SANTA MARÍA}

Otro apelativo que antaño tuvo esta plaza fué la de Llano de Santa María, nombre que vinculaba su ámbito occidental a la iglesia mayor colegial de la ciudad.

La plaza Vázquez de Molina, de estructura original más abierta y despejada, no obstante estaba constituida por la simbiosis de diversos recintos armónicamente articulados.

El Salvador marcaba un evidente eje de axialidad y preeminencia visual en convivencia con elementos asimétricos propios de tramas urbanas preexistentes. Aquí el espacio no está - no puede estar- organizado como un sistema unitario, sino como la acumulación de sistemas menores, cuya principal referencia está en los hitos monumentales claramente jerarquizados, 


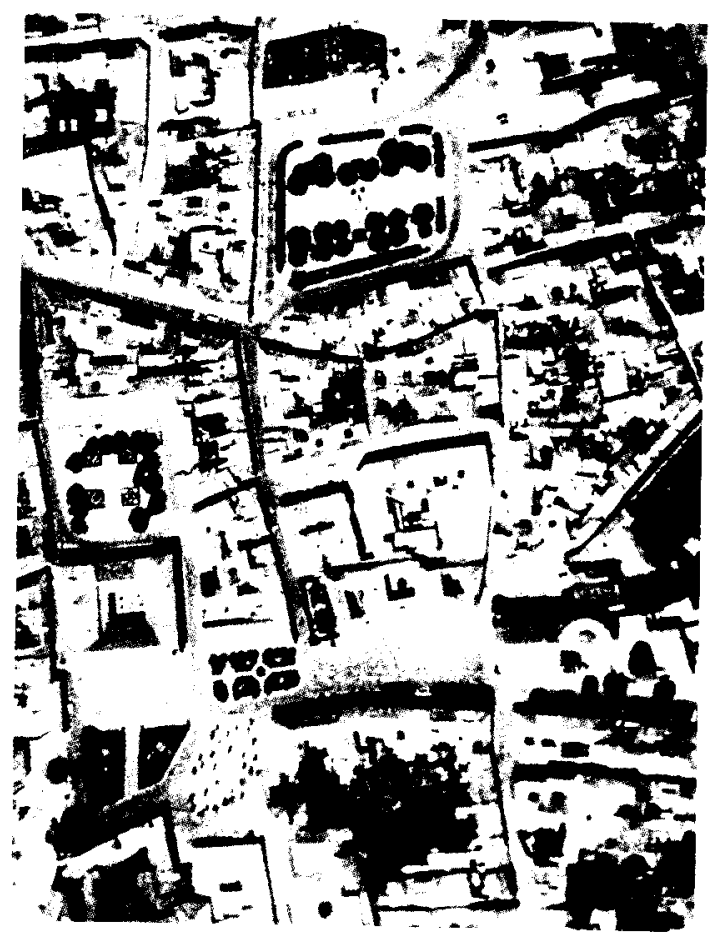

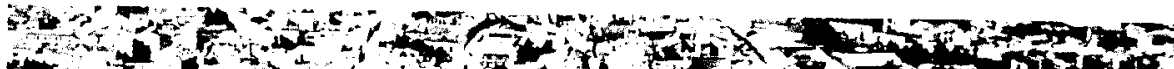

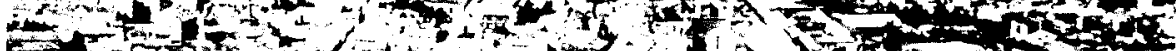

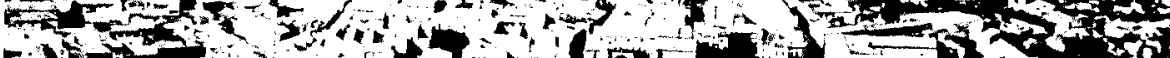

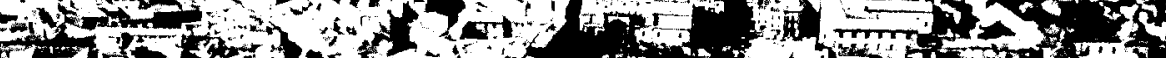

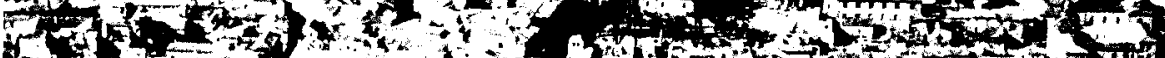

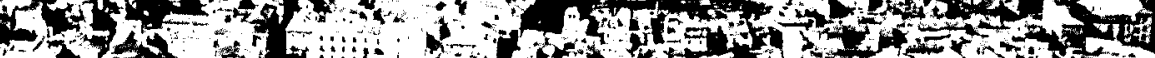

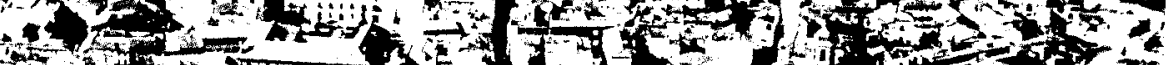

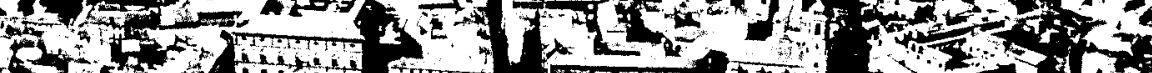

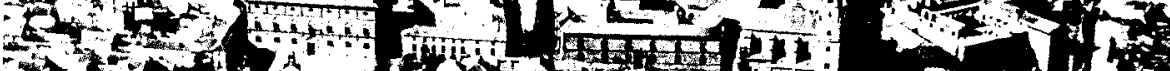

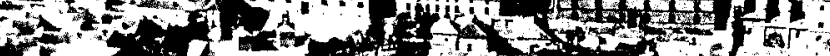

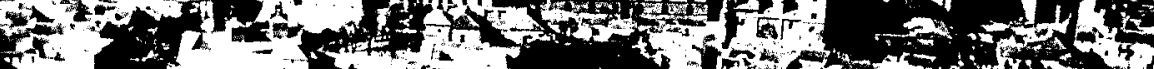

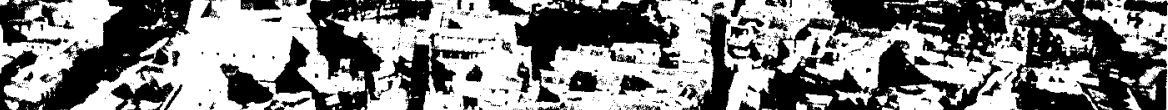

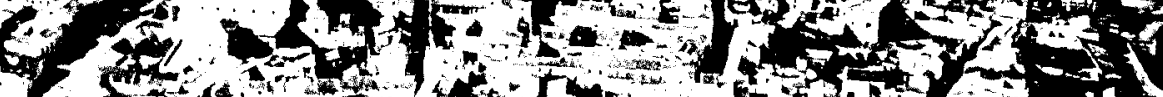

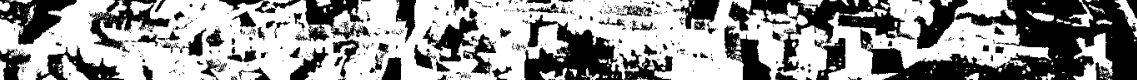
(1) 
fenómeno éste que había encontrado en Europa precedentes tan elocuentes como el caso de Urbino.
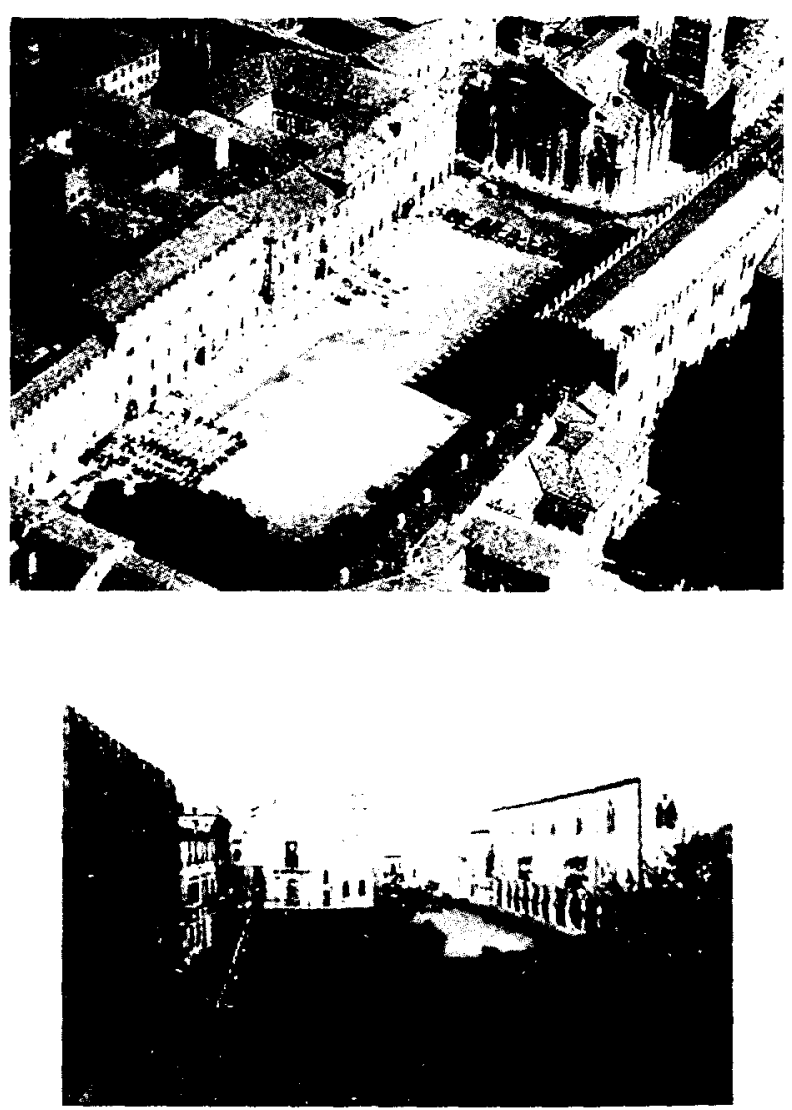

Un segundo espacio organizativo convecino al principal viene establecido por la presencia de un doble eje perpendicular de axialidad. Este sería el definido por las fachadas del palacio Vázquez de Molina y Santa María de los Reales Alcázares y la portada lateral de dicho templo con la fachada de la Torre del Tesorero.

La importancia de este segundo ámbito, dominado elocuentemente por el nuevo eje fijado por el palacio Vázque de Molina, fenómeno que casi origina la presencia de una segunda plaza, conseguía atenuar por parte de éste -en palabras de Marín de Terán- su condición de pieza subsidiada al templo del Salvador, "colocándose como protagonista de su propio 
"subespacio" e introduciendo un vector de complejidad en el conjunto, cuya planta en $L$ tambien se presenta en algunas plazas de reestructuración de las ciudades renacentistas italianas" ${ }^{37}$.

\section{El Palacio Vázquez de Molina}

El palacio Vázquez de Molina, tambien conocido como Palacio de las Cadenas, fué mandado construir por don Juan Vázquez de Molina, sobrino-ahijado de Francisco de los Cobos y fiel continuador de su «patrón» en las tareas políticas y administrativas al servicio de la Corona. Secretario de Estado y Cámara de Felipe II, Juan Vázquez constituye un eslabón más dentro de esta extraordinaria saga familiar de los Molina, verdaderos artífices del Renacimiento ubetense.

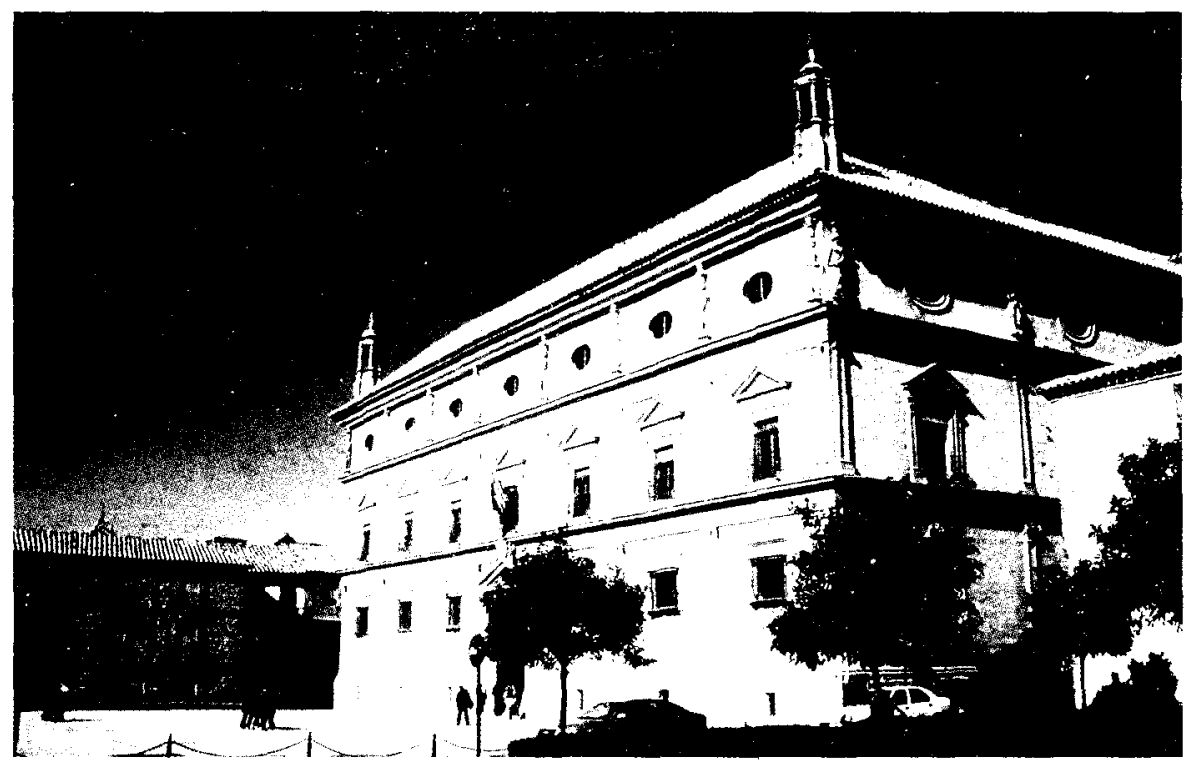

Las obras del palacio debieron dar comienzo a finales de los años treinta, cuando su promotor compraba a la ciudad varias fincas urbanas

37 Marin de Teran. L.: "El urbanismo Renacentista en las ciudades de Úbeda y Baeza". Propuesta de inscripción en la lista de Patrimonio de la Humanidad. Ayuntamiento de Úbeda, Ayuntamiento de Baeza, Junta de Andalucia, 1999, pág. 14. 
-entre ellas la cácel vieja- para ser convertidas con posterioridad en solar.

Su fachada debe estar bastante avanzada en 1546, toda vez que este año son encargados los trabajos de rejería de la misma ${ }^{38}$. Una década más tarde, dos canteros locales, Antón Sánchez y Alonso Fernandez, se obligan a levantar los muros laterales de la fachada, perdurando la construcción - bien es verdad que a un nivel de trabajos complementariosdurante la década de los sesenta.

Vandelvira, su tracista y constructor, va a plantear el diseño de su gran fachada, tambien el de la estructura general del edificio, siguiendo el modelo fijado en 1511 por Fra Giocondo para su modelo de "casa romana" en su edición de Vitruvio ${ }^{39}$.

A pesar de la presumible ingenuidad de la propuesta, a pesar tambien de la precocidad de la fecha, Vandelvira pone de manifiesto un alto grado de madurez compositiva y un evidente instinto clasicista en esta obra, pues hablamos del primer modelo palaciego surgido en la ciudad con verdadera vocación cúbica y exenta.

En su diseño se desarrolla de manera reglada y coherente un planteamiento orgánicamente estructurado, correspondiendo a cada planta - tras un zócalo- un orden arquitectónico diferente. Esta, deudora por su compartimentación vertical de la concepción albertiana, presenta en su tercer cuerpo soportes antropomórficos, en sustitución de las pilastras, préstamo literario de la edición vitruviana de Césare Cesariano (Como, 1521). Esta cariátides y telamones parecen recordarnos las ilustraciones de Piero Apianus (Inscriptiones Sacrosanctae), de 1534, libro que figuraba entre las pertenecias de Andrés de Vandelvira. Completa la fachada una potente y volada cornisa rematada en sus vértices laterales por una elegantes y originales linternas - a modo de tholoi clásicos-, posíblemente inspiradas en las linternas eclesiásticas que aparecen en el Libro IV de Serlio (1547) ${ }^{40}$.

\section{Santa Maria de los Reales Alcázares}

Frente a este palacio se extiende la fachada de la Colegiata.

38 Gila Medina, L. y Ruiz Fuentes, V.M.: «Andrés de Vandelvira. Aproximación a su vida y obra". Catálogo de la exposición "Arquitectura del renacimiento en Andalucia. Andrés de Van" delvira y su época". Jaén, 1992, pág. 92.

39 Fra Giocondo di Verona.: $M$. Vitruvii De Architectura. Libri decem nuper maxima... Liber primus, Venecia, 1511, pág. 11.

40 Marias, F.: El largo siglo xvi. Taurus, Madrid. 1987, pág. 415. 
Santa María de los Reales Alcázares es un venerable y medieval edificio cuya fachada principal, perimetral al claustro de la iglesia, es encargada en 1604 por el canónigo don Antonio Molina Valenzuela a su maestro y tracista Martín López de Alcaraz, interviniendo en las obras los canteros Pedro del Cabo el Viejo y su hijo, Pedro del Cabo el Mozo ${ }^{41}$.

El proyecto consistía en una retórica fachada «de doce pies de claro en proporcion de tres y cinco" que, a manera de pantalla, recubriera los muros de la sólida muralla -dentro de cuyo recinto se encontraba el templo-, sin mayores - ni posibles- pretensiones de ordenar la estructura.

Para llevar a buen término esta empresa edilicia, patrocinada directamente por el obispo don Sancho Dávila, es desechada la puerta de la anterior e inconclusa fachada, promovida a principios de siglo por el prelado don Alonso Suarez de la Fuente del Sauce. Su finalidad, hacer coincidir ésta, estableciendo un nuevo eje de simetría, con la Portada del Palacio de las Cadenas, en aquellos años ya monasterio de dominicas de la Madre de Dios.

La nueva obra, en la que al parecer tambien interviene el cantero Pedro de Alarcos, debe estar concluida en 1612, pues en este año es redactado un nuevo pliego de condiciones para la construcción de un pretil o antepecho que constituyese una nueva lonja precedida de gradas. Este dato evidencia la existencia, aún, de un claro desnivel del terreno con respecto al «llano» de la plaza ${ }^{42}$.

El segundo eje de este ámbito conectaría la portada lateral del templo, conocida como de La Consolada, y la Torre del Tesorero, llamado en la actualidad Palacio del Marqués de Mancera, su posterior propietario.

La portada colegial, que repite el esquematisco de arco triunfal y serliana de otras portadas locales como la de San Pedro, tambien había sido trazada por Martín López de Alcaraz, corriendo su labra a cargo de los canteros Pedro del Cabo y Cristobal del Pozo ${ }^{43}$.

La Torre del Tesorero era, a su vez, erigida por los hermanos Hernando de Herrera y Lope de Molina Valenzuela, canónigos de la colegial, en el último cuarto del xvI.

\footnotetext{
41 Almagro Gaficia. Santa Maria... Op. cit., pág. 20.

42 Almagro Garcia. A. y Ruiz Fuentes, V.M.: "Santa María de los Reales Alcázares y su relación con el Alcázar de Úbeda». Rev. Ibiut. Año Vl. núm. 29, pág. 25

43 Almagro Garcia. Santa María... Op. cit., pág. 21.
} 


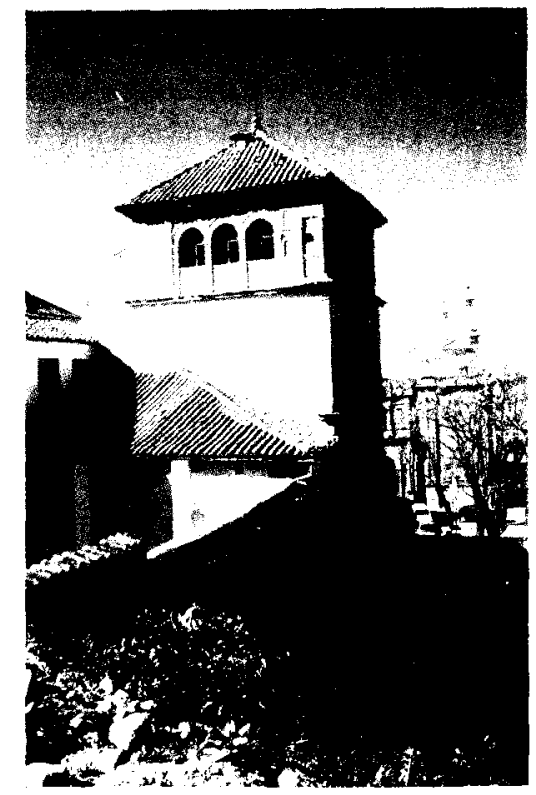

Concebída la mansión como alcázar urbano, proyecta hacia poniente su única portada, una réplica de la vandelviriana portada del palacio Vela de los Cobos, afrontada a la Consolada y en ángulo recto con la sobria fachada del emparedamiento de Sancho Iñiguez o Cárcel del Obispo.

El esfuerzo constructivo y configurador de un nuevo espacio urbano es tan patente que ya, entre 1580 y 1590, los canónigos de la Colegiata, hasta entonces próspera parroquia de la ciudad, se verán forzados a abrir una información para probar la disminución de sus diezmos. En esta se pone de manifiesto que una de las causas - si no la mayor- de su progresiva pobreza paradójicamente "era debida al derribo de muchas casas para hacer la capilla del Sagrario, la de Santiago, el palacio-convento de Vázquez de Molina, el de don Fernando Ortega y otras, para hacer plaza pública..." ${ }^{44}$.

No pensemos que la desaparición de estas viviendas había afectado sólo a pobladores humildes, pues ya en el documento los prebendados confirman que los feligreses, ahora emigrados a otras collaciones de la población, eran hombre ricos "y tenian heredades y posesiones". Eran

44 Ruiz Prieto: Op. cit., pág. 317. 
vecinos acomodados, de posible origen judeoconverso; pero es obvio que no pertenecian a la oligarquía local. El patriciado urbano, y sobre todo un grupo de poder como la prestigiosa familia Cobos-Molina, promotora tambien de otros palacios en la ciudad como el Vela de los Cobos o el de don Francisco de Molina (hoy conocido como Marqués de la Rambla), había transformado la ciudad en su vértice sur.

En un plazo de tiempo no superior a setenta años había surgido uno de los conjuntos renacentistas más prodigiosos de España. Por fín la ciudad, protagonista de su historia, podía disponer de un espacio aúlico para la representación de sus más conspicuos linajes, un asombroso marco escénico para celebrar su propia eternidad. 